\title{
Alkylthio substituted thiophene modified benzodithiophene-based highly efficient photovoltaic small molecules
}

\section{Graphical abstract}

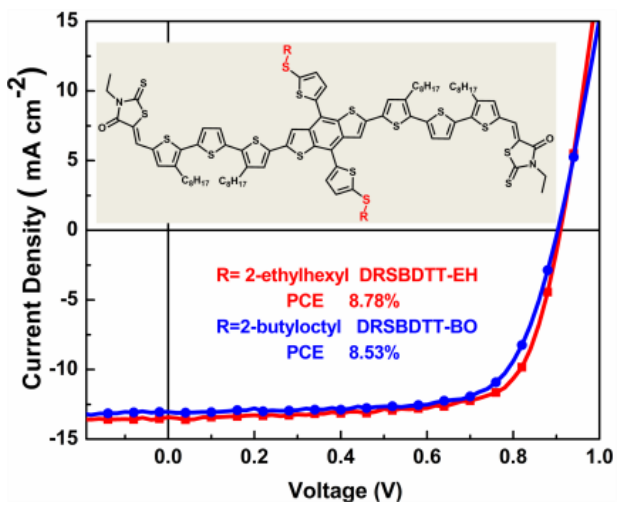




\section{Alkylthio substituted thiophene modified benzodithiophene-based highly efficient photovoltaic small molecules}

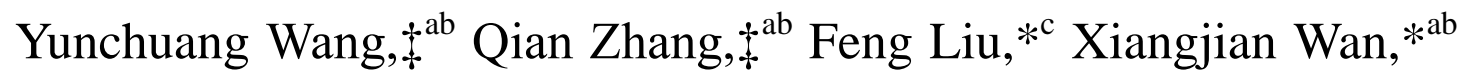

Bin Kan, ${ }^{\text {ab }}$ Huanran Feng, ${ }^{\text {ab }}$ Xuan Yang, ${ }^{\text {ab }}$ Thomas P. Russell ${ }^{\text {cd }}$ and Yongsheng Chen*ab

${ }^{a}$ State Key Laboratory and Institute of Elemento-Organic Chemistry, Collaborative Innovation Center of Chemical Science and Engineering (Tianjin), Nankai University, Tianjin 300071, China.

${ }^{b}$ Key Laboratory of Functional Polymer Materials and the Centre of Nanoscale Science and Technology, Institute of Polymer Chemistry, College of Chemistry, Nankai University, Tianjin, 300071, China.

${ }^{\mathrm{c}}$ Materials Science Divisions, Lawrence Berkeley National Lab, Berkeley 94720, United States.

${ }^{\mathrm{d}}$ Department of Polymer Science and Engineering, University of Massachusetts, Amherst 01003, United States.

*Corresponding authors. Fax: +86-(22)-2349-9992. E-mail: yschen99@nankai.edu.cn (Y. Chen), xjwan@nankai.edu.cn (X. Wan), iamfengliu@gmail.com (F, Liu). 


\section{Abstract}

Two new small molecules, namely DRSBDTT-EH and DRSBDTT-BO, with alkylthio thienyl substituted benzodithiophene as the central unit and 3-ethylrhodanine as end groups, were designed and studied as the donors for solution processed organic solar cells. The optimized device based on DRSBDTT-EH bearing shorter alkylthio chain gave a power conversion efficiency (PCE) of $8.78 \%$, which is slightly higher than that of device $(8.53 \%)$ based on DRSBDTT-BO with longer alkylthio chain.

\section{Key words}

Organic solar cell, small molecule, solution processed, alkylthio chain. 


\section{Introduction}

The solution-processed bulk heterojunction organic photovoltaic cells (OPVs), one of the most promising candidate alternatives to inorganic solar cells, have been well developed in the past decades, due to the promising advantages such as low cost, lightweight, flexiblity and etc [1-4]. With the unremitting efforts, the power conversion efficiencies (PCEs) of solution processed polymer and fullerence derivatives based OPVs (P-OPVs) have been improved up to $10 \%$ for single-junction solar cells [5-10], and the non-fullerene acceptor based OPVs also achieved great progress $[11,12]$, such as the PDI and NDI-based n-type polymers [13-17]. Small-molecule based OPVs (SM-OPVs) [18-20], started at a later stage in OPV research, show some unique advantages, including well-defined structure and thus less batch-to-batch variation, versatile chemical structures and thus easier energy level control, etc [21-23]. SM-OPVs have established a milestone PCE over $10 \%$ in our most recent effort [24], demonstrating a successful example of molecular design in optimizing desired properties in organic functional materials.

Benzo[1,2-b:4,5-b']dithiophene (BDT) units and the alkylthienyl substituted BDT (BDTT) units have been widely used to construct highly efficiencient photovoltaic polymers and small molecules. 
[25-27] For example, the polymer PTB7 and PTB7-Th, constructed from BDT and TT unit, have achieved over 10\% PCE [28-33]. In SM-OPVs, we have designed a series of high performance small molecule donor materials incorporating BDT and BDTT unit $[34,35]$. In decorating BDT and BDTT units, alkylthio side chains have been introduced and the resulting organic semiconductors exhibit unique optoelectronic properties and better ordered molecular packing [36-38]. In our recent effort in introducing alkylthio side chain to BDT unit, we recently have reported DR3TSBDT and achieved PCE of $9.95 \%$ [39].

In this work, we have developed two new small molecules (Scheme 1), namely DRSBDTT-EH and DRSBDTT-BO, of using alkylthiol flexible side chain to function BDTT based thiophene-conjugated small molecules [40]. DRSBDTT-EH with 2-ethylhexylthio as side chain has relatively low solubility in common organic solvent such as chloroform (CF) and chlorobenzene at room temperature. The $\mathrm{CF}$ blend solution of DRSBDTT-EH and PCBM needs to be heated at $50{ }^{\circ} \mathrm{C}$ for $0.5 \mathrm{~h}$ before spin-coating during device fabrication. In order to ensure sufficient solubility for efficient device fabrication, another small molecule DRSBDTT-BO, increasing the side chain length of the BDTT core of DRSBDTT-EH for better solubility was designed. 
Through device optimization, the two molecules all showed PCEs of over $8 \%$ when used as the donors in the devices with $\mathrm{P}_{71} \mathrm{CBM}$ as the acceptor.

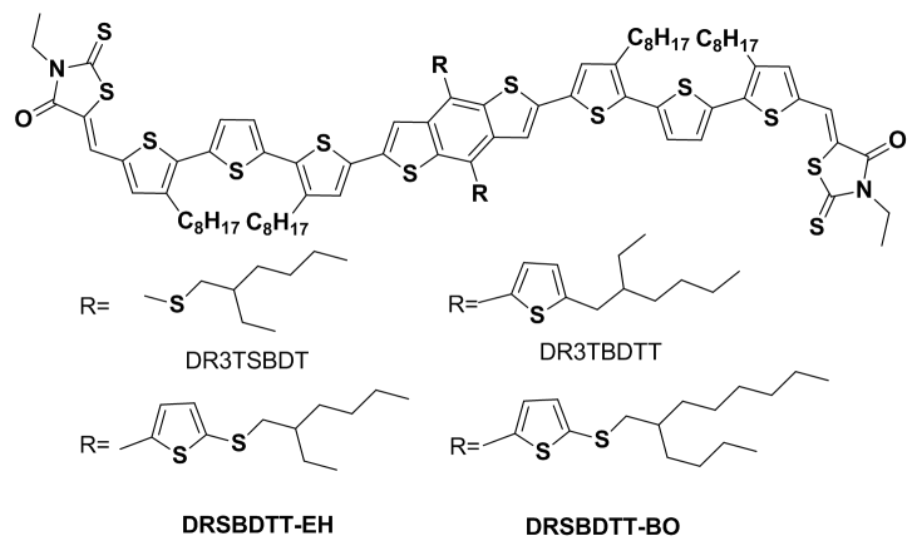

Scheme 1 Chemical structures of DR3TSBDT, DR3TBDTT, DRSBDTT-EH and DRSBDTT-BO.

\section{Experimental section}

\subsection{Materials and Synthesis}

All reactions and manipulations were carried out under argon atmosphere with the use of standard Schlenk tube techniques. All starting materials were used as purchased from commercial sources unless stated otherwise. Toluene was distilled from sodium and benzophenone under an $\mathrm{Ar}$ atmosphere. $\mathrm{CHCl}_{3}$ was dried over anhydrous $\mathrm{Na}_{2} \mathrm{SO}_{4}$. Compounds $\mathbf{1}$ and $\mathbf{2}$ were synthesized according to the literatures $[41,42]$. 


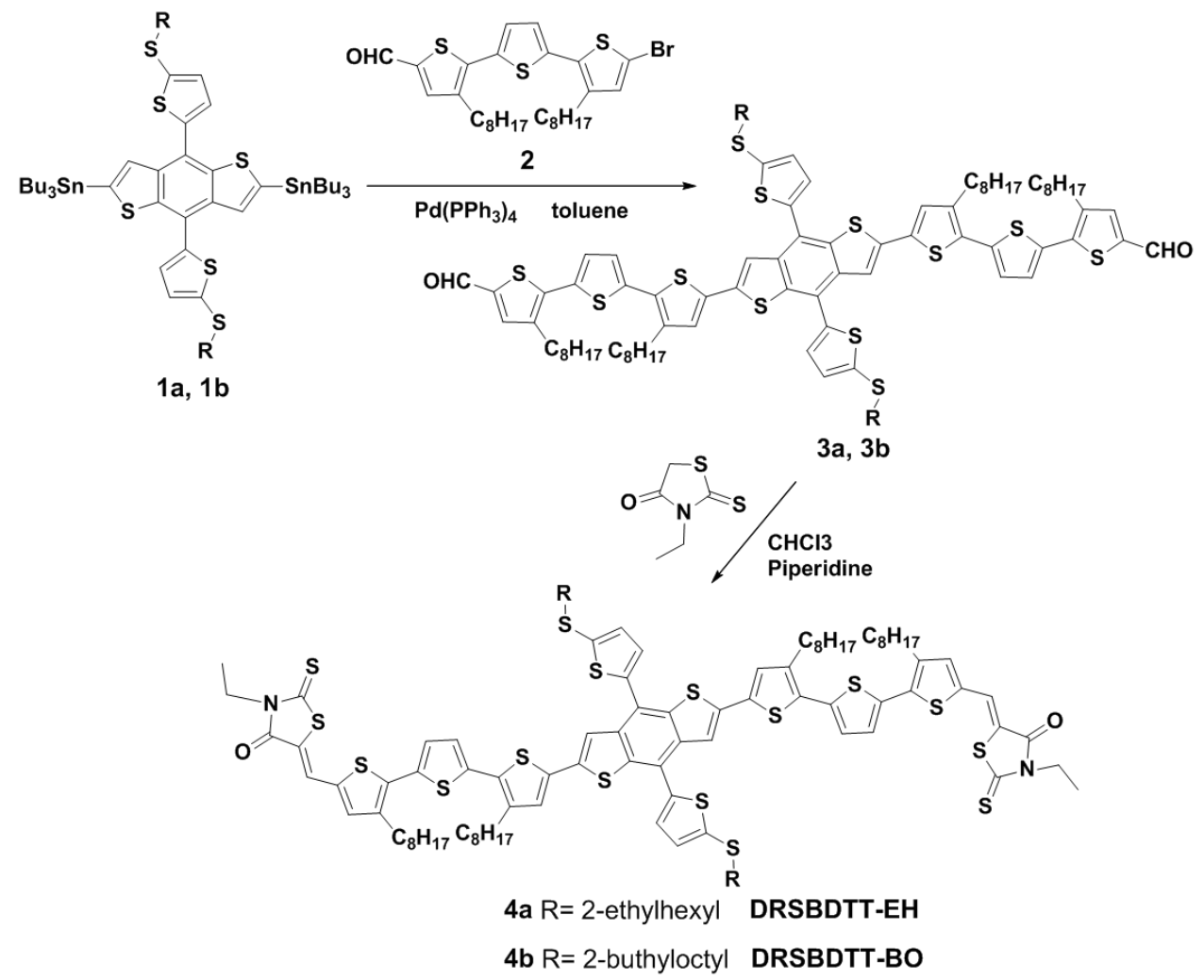

Scheme 2 Synthetic routes of DRSBDTT-EH and DRSBDTT-BO

Compound 3a: A solution of compound 1a (2.44 g, 2 mmol), and compound 2 (2.43 g, $4.2 \mathrm{mmol})$ in dry toluene was degassed twice followed by the addition of $\mathrm{Pd}\left(\mathrm{PPh}_{3}\right)_{4}(0.12 \mathrm{~g}, 0.1 \mathrm{mmol})$ under the protection of argon. After stirring and refluxing for $24 \mathrm{~h}$, the mixture was extracted with $\mathrm{CH}_{2} \mathrm{Cl}_{2}(50 \mathrm{ml} \times 3)$. The organic layer was washed with water and dried with anhydrous $\mathrm{Na}_{2} \mathrm{SO}_{4}$ for $3 \mathrm{~h}$. After the removal of solvent, the crude product was purified by silica gel using the mixture of dichloromethane and petroleum $(2: 1)$ as eluent to afford compound 3a as a red solid (2.00 g, 61\%). ${ }^{1} \mathrm{H}$ NMR (400 $\left.\mathrm{MHz}, \mathrm{CDCl}_{3}\right): \delta 9.83(\mathrm{~s}, 2 \mathrm{H}), 7.60(\mathrm{~s}, 2 \mathrm{H}), 7.57(\mathrm{~s}, 2 \mathrm{H}), 7.34(\mathrm{~d}, 2 \mathrm{H})$, $7.24(\mathrm{~d}, 4 \mathrm{H}), 7.12(\mathrm{~d}, 4 \mathrm{H}), 2.99(\mathrm{~d}, 4 \mathrm{H}), 2.84-2.74(\mathrm{~m}, 8 \mathrm{H}), 1.72-1.64$ 
(m, 10H), 1.58-1.46 (m, $16 \mathrm{H}), 1.34-1.25(\mathrm{~m}, 40 \mathrm{H}), 0.97-0.86(\mathrm{~m}$, 24H). ${ }^{13} \mathrm{C} \mathrm{NMR}\left(100 \mathrm{MHz}, \mathrm{CDCl}_{3}\right): \delta$ 182.44, 141.61, 140.95, $140.90,140.18,140.07,139.11,138.47,137.94,137.81,137.64$, $137.14,135.17,134.68,132.40,130.53,128.47,128.40,127.66$, $126.02,122.63,118.51,43.49,39.33,32.18,31.96,31.92,30.45$, $30.25,29.80,29.74,29.60,29.53,29.50,29.38,29.32,28.81,25.45$, 23.03, 22.74, 22.72, 14.18, 10.99. MS (MALDI-TOF) m/z: calcd for $\mathrm{C}_{92} \mathrm{H}_{118} \mathrm{O}_{2} \mathrm{~S}_{12}[\mathrm{M}]^{+}$, 1638.58; found, 1638.58.

Compound DRSBDTT-EH: 3a (0.32 g, $0.2 \mathrm{mmol})$ and 3-ethyl rhodanine $(0.32 \mathrm{~g}, 2 \mathrm{mmol})$ was dissolved in a dry $\mathrm{CHCl}_{3}(40 \mathrm{~mL})$ solution, and then three drops of piperidine was added to the mixture under the protection of argon. After stirring and refluxing for $12 \mathrm{~h}$, the mixture was extracted with $\mathrm{CHCl}_{3}(50 \mathrm{ml} \times 3)$, and the organic layer was washed with water and dried over anhydrous $\mathrm{Na}_{2} \mathrm{SO}_{4}$ for 3 h. After removal of solvent, the crude product was purified by silica gel using chloroform as eluent and then recrystallized from $\mathrm{CHCl}_{3}$ to afford DRSBDTT-EH as a black solid $(0.25 \mathrm{~g}, 65 \%) .{ }^{1} \mathrm{H}$ NMR $\left(400 \mathrm{MHz}, \mathrm{CDCl}_{3}\right): \delta 7.72(\mathrm{~s}, 2 \mathrm{H}), 7.49(\mathrm{~s}, 2 \mathrm{H}) 7.33(\mathrm{~d}, 2 \mathrm{H}), 7.27(\mathrm{~s}$, 2H), $7.18(\mathrm{~d}, 4 \mathrm{H}), 7.06(\mathrm{~s}, 2 \mathrm{H}), 7.04(\mathrm{~s}, 2 \mathrm{H}), 4.19-4.14(\mathrm{~m}, 4 \mathrm{H}), 3.01$ (d, $2 \mathrm{H}), 2.80-2.71(\mathrm{~m}, 8 \mathrm{H}), 1.71-1.64(\mathrm{~m}, 10 \mathrm{H}), 1.58-1.25(\mathrm{~m}, 58 \mathrm{H})$, 0.99-0.87 (m, 30H). $\left.{ }^{13} \mathrm{C} \mathrm{NMR} \mathrm{(100} \mathrm{MHz,} \mathrm{CDCl}_{3}\right): \delta$ 192.02, 167.30, $141.59,141.07,141.01,139.41,138.63,137.99,137.44,137.30$, 
$135.24,132.46,130.73,129.16,128.54,128.47,127.25,126.26$, $124.85,122.79,120.60,118.65,43.50,39.31,32.15,31.91,31.88$, $30.45,30.25,29.72,29.57,29.49,29.31,29.45,29.40,28.79,25.44$, 22.99, 22.69, 14.14, 12.30, 10.95. MS (MALDI-TOF) m/z: calcd for $\mathrm{C}_{102} \mathrm{H}_{128} \mathrm{~N}_{2} \mathrm{O}_{2} \mathrm{~S}_{16}[\mathrm{M}]^{+}, 1924.55$; found, 1924.51.

Compound 3b: A solution of compound $\mathbf{1 b}(2.67 \mathrm{~g}, 2 \mathrm{mmol})$, and compound 2 (2.46 g, $4.2 \mathrm{mmol}$ ) in dry toluene was degassed twice followed by the addition of $\mathrm{Pd}\left(\mathrm{PPh}_{3}\right)_{4}(0.12 \mathrm{~g}, 0.1 \mathrm{mmol})$ under the protection of argon. After stirring and refluxing for $24 \mathrm{~h}$, the mixture was extracted with $\mathrm{CH}_{2} \mathrm{Cl}_{2}(50 \mathrm{ml} \times 3)$. The organic layer was washed with water and dried with anhydrous $\mathrm{Na}_{2} \mathrm{SO}_{4}$ for $3 \mathrm{~h}$. After the removal of solvent, the crude product was purified by silica gel using the mixture of dichloromethane and petroleum (2:1) as eluent to afford compound $\mathbf{3 b}$ as a red solid $(1.80 \mathrm{~g}, 51 \%) .{ }^{1} \mathrm{H}$ NMR (400 $\mathrm{MHz}, \mathrm{CDCl}_{3}$ ): $\delta 9.83$ (s, 2H), 7.60 (s, 2H), 7.57 (s, 2H), 7.34(d, 2H), $7.24(\mathrm{~d}, 4 \mathrm{H}), 7.12(\mathrm{~d}, 4 \mathrm{H}), 2.99(\mathrm{~d}, 4 \mathrm{H}), 2.84-2.74(\mathrm{~m}, 8 \mathrm{H}), 1.72-1.64$ (m, 10H), 1.58-1.46 (m, $24 \mathrm{H}), 1.34-1.25$ (m, 40H), 0.97-0.86 (m, 24H). ${ }^{13} \mathrm{C}$ NMR $\left(100 \mathrm{MHz}, \mathrm{CDCl}_{3}\right): \delta 182.23,141.57,140.92$, $140.75,140.06,138.98,138.38,138.06,137.81,137.52,137.07$, $135.12,134.64,132.19,130.54,128.49,128.28,127.51,125.88$, $122.54,118.46,44.03,37.98,33.07,32.71,32.00,31.92,30.44$, $30.22,29.88,29.70,29.66,29.58,29.54,29.44,29.35,28.85,26.61$, 
23.07, 22.78, 14.19. MS (MALDI-TOF) m/z: calcd for $\mathrm{C}_{100} \mathrm{H}_{134} \mathrm{O}_{2} \mathrm{~S}_{12}$ $[\mathrm{M}]^{+}, 1750.70$; found, 1750.68 .

Compound DRSBDTT-BO: 3b (0.32 g, $0.2 \mathrm{mmol})$ and 3-ethyl rhodanine $(0.32 \mathrm{~g}, 2 \mathrm{mmol})$ was dissolved in a dry $\mathrm{CHCl}_{3}(40 \mathrm{~mL})$ solution, and then three drops of piperidine was added to the mixture under the protection of argon. After stirring and refluxing for $12 \mathrm{~h}$, the mixture was extracted with $\mathrm{CHCl}_{3}(50 \mathrm{ml} \times 3)$, and the organic layer was washed with water and dried over anhydrous $\mathrm{Na}_{2} \mathrm{SO}_{4}$ for 3 h. After removal of solvent, the crude product was purified by silica gel using chloroform as eluent and then recrystallized from $\mathrm{CHCl}_{3}$ to afford DRSBDTT-BO as a black solid (0.25 g, 65\%). ${ }^{1} \mathrm{H}$ NMR $\left(400 \mathrm{MHz}, \mathrm{CDCl}_{3}\right): \delta 7.72(\mathrm{~s}, 2 \mathrm{H}), 7.52(\mathrm{~s}, 2 \mathrm{H}) 7.33(\mathrm{~d}, 2 \mathrm{H}), 7.27(\mathrm{~s}$, 2H), 7.18 (d, 4H), 7.09 (d, 2H), 7.07 (s, 2h), 4.19-4.14 (m, 4H), 3.01 (d, 2H), 2.80-2.71 (m, 8H), 1.78-1.66 (m, 10H), 1.58-1.25 (m, 66H), 0.99-0.87 (m, 30H). ${ }^{13} \mathrm{C}$ NMR (100 MHz, $\left.\mathrm{CDCl}_{3}\right): \delta$ 191.92, 167.20, $141.54,140.86,140.76,139.49,138.48,138.02,137.64,137.44$, $137.24,137.17,135.10,135.05,134.75,132.27,130.73,129.16$, $128.42,127.06,126.02,124.71,122.64,120.47,118.53,43.99$, $39.88,37.90,33.00,32.65,31.92,31.90,31.87,30.43,30.19,29.84$, $29.78,29.71,29.64,29.58,29.53,29.49,29.37,29.32,28.80,26.55$, 23.01, 22.72, 14.20, 14.14, 12.30. MS (MALDI-TOF) m/z: calcd for $\mathrm{C}_{110} \mathrm{H}_{144} \mathrm{~N}_{2} \mathrm{O}_{2} \mathrm{~S}_{18}[\mathrm{M}]^{+}, 2039.37$; found, 2039.42. 


\subsection{Measurements and instruments}

The ${ }^{1} \mathrm{H}$ and ${ }^{13} \mathrm{C}$ NMR spectra were recorded on a Bruker AV400 Spectrometer. Matrix assisted laser desorption/ionization time-of-flight mass spectrometry (MALDI-TOF) were performed on a Bruker Autoflex III LRF200-CID instrument. The thermogravimetric analysis (TGA) was carried out on a NETZSCH STA 409PC instrument under purified nitrogen gas flow with a $10{ }^{\circ} \mathrm{C} \min ^{-1}$ heating rate. UV-Vis spectra were obtained with a JASCO V-570 spectrophotometer. Cyclic voltammetry (CV) experiments were performed with a LK98B II Microcomputer-based Electrochemical Analyzer. All CV measurements were carried out at room temperature with a conventional three-electrode configuration employing a glassy carbon electrode as the working electrode, a saturated calomel electrode (SCE) as the reference electrode, and a Pt wire as the counter electrode. Dichloromethane was distilled from calcium hydride under dry nitrogen immediately prior to use. Tetrabutylammonium phosphorus hexafluoride $\left(\mathrm{Bu}_{4} \mathrm{NPF}_{6}, 0.1 \mathrm{M}\right)$ in dichloromethane was used as the supporting electrolyte, and the scan rate was $100 \mathrm{mV} \mathrm{s}^{-1}$.

Atomic force microscopy (AFM) was performed using Multimode 8 atomic force microscope in tapping mode. The 
transmission electron microscopy (TEM) investigation was performed on Philips Technical $\mathrm{G}^{2} \mathrm{~F} 20$ at $200 \mathrm{kV}$. The specimen for TEM measurement was prepared by spin casting the blend solution on ITO/PEDOT:PSS substrate, then floating the film on a water surface, and transferring to TEM grids. Grazing incidence X-ray diffraction (GIXD) characterization of the thin films was performed at beamline 7.3.3 Lawrence Berkeley National Lab. The scattering signal was recorded on a 2-D detector (Pilatus $1 \mathrm{M}$ ) with a pixel size of $172 \mu \mathrm{m}, 91$ by 1043 array. The X-ray energy is $10 \mathrm{keV}$. The samples were $\sim 15 \mathrm{~mm}$ long in the direction of the beam path, and the detector was located at a distance of $320 \mathrm{~mm}$ from the sample center (distance calibrated using a silver behenet standard). The incidence angle of $0.18^{\circ}$ was chosen which gave the optimized signal-to-background ratio. Thin film samples were prepared on PEDOT:PSS covered silicon wafers to match the device conditions. The data was processed and analyzed using Nika software package. Space charge limited current (SCLC) mobility was measured using a diode configuration of ITO/PEDOT:PSS/donor:PC ${ }_{71} \mathrm{BM} / \mathrm{Au}$ for hole by taking the dark current density in the range of 0-6 $\mathrm{V}$ and fitting the results to a space charge limited form, where SCLC equation is described by: 


$$
J=\frac{9 \varepsilon_{0} \varepsilon_{r} \mu_{0} V^{2}}{8 L^{3}} \exp \left(0.89 \beta \sqrt{\frac{V}{L}}\right)
$$

where $J$ is the current density, $L$ is the film thickness of the active layer, $\mu_{0}$ is the hole mobility, $\varepsilon_{\mathrm{r}}$ is the relative dielectric constant of the transport medium, $\varepsilon_{0}$ is the permittivity of free space $(8.85 \times$ $\left.10^{-12} \mathrm{~F} \mathrm{~m}^{-1}\right), V\left(=V_{\mathrm{appl}}-V_{\mathrm{bi}}\right)$ is the internal voltage in the device, where $V_{\text {appl }}$ is the applied voltage to the device and $V_{\mathrm{bi}}$ is the built-in voltage due to the relative work function difference of the two electrodes.

\subsection{Fabrication of organic solar cells}

The devices were fabricated with a structure of glass/ITO/PEDOT:PSS/donor:acceptor/PrC ${ }_{60} \mathrm{MA} / \mathrm{Al}$ The ITO-coated glass substrates were cleaned by ultrasonic treatment in detergent, deionized water, acetone, and isopropyl alcohol under ultra-sonication for 15 minutes each and subsequently dried by a nitrogen blow. A thin layer of PEDOT:PSS (Clevios P VP AI 4083, filtered at $0.45 \mu \mathrm{m}$ ) was spin-coated at $3000 \mathrm{rpm}$ onto ITO surface. After baked at $150{ }^{\circ} \mathrm{C}$ for 20 minutes, the substrates were transferred into an argon-filled glove box. All blend solutions of donor and $\mathrm{PC}_{71} \mathrm{BM}$ were stirred overnight. Specially, DRSBDTT-EH/PC ${ }_{71} \mathrm{BM}$ solution was heated at $50{ }^{0} \mathrm{C}$ for $0.5 \mathrm{~h}$ before spin-coating. The substrates were placed in a glass petri dish containing $150 \mathrm{uL} \mathrm{CS} \mathrm{CS}_{2}$ for 1 minute for solvent vapor annealing (SVA). Then the substrates 
were removed. And $\operatorname{PrC}_{60} \mathrm{MA}$ solution $(0.2 \mathrm{mg} / \mathrm{ml}$, dissolved in methanol) was spin-coated at $3000 \mathrm{rpm}$. Finally, $80 \mathrm{~nm} \mathrm{Al} \mathrm{layer}$ were deposited under high vacuum $\left(<2 \times 10^{-4} \mathrm{~Pa}\right)$. The effective areas of cells were $4 \mathrm{~mm}^{2}$ defined by shadow masks. The current density-voltage $(J-V)$ curves of photovoltaic devices were obtained by a Keithley 2400 source-measure unit. All masked and unmasked tests gave consistent results with relative errors within 5\%. The photocurrent was measured under illumination simulated AM 1.5G $\left(100 \mathrm{~mW} \mathrm{~cm}^{-2}\right.$ ) irradiation using an Oriel 96000 solar simulator, calibrated with a standard $\mathrm{Si}$ solar cell. The average PCE was obtained using 20 devices under the same conditions. External quantum efficiencies were measured using Stanford Research Systems SR810 lock-in amplifier. The thickness of the active layers in the photovoltaic devices was measured on a Veeco Dektak 150 profilometer.

\section{Results and discussion}

\subsection{Synthesis and thermal property}

The synthetic procedures for DRSBDTT-EH and DRSBDTT-BO are presented in Scheme 1. These two molecules were synthesized through typical Stille Coupling and Knoevenagel condensation reactions and their structures had been characterized by NMR spectroscopy, mass spectrometry and etc. 
Thermogravimetric analysis (TGA) suggests that both of two materials show good thermal stability with a $5 \%$ weight loss $\left(T_{\mathrm{d}}\right)$ occurring over $395^{\circ} \mathrm{C}$ under nitrogen atmosphere (Fig. S1).

\subsection{Optical properties and electrochemical properties}
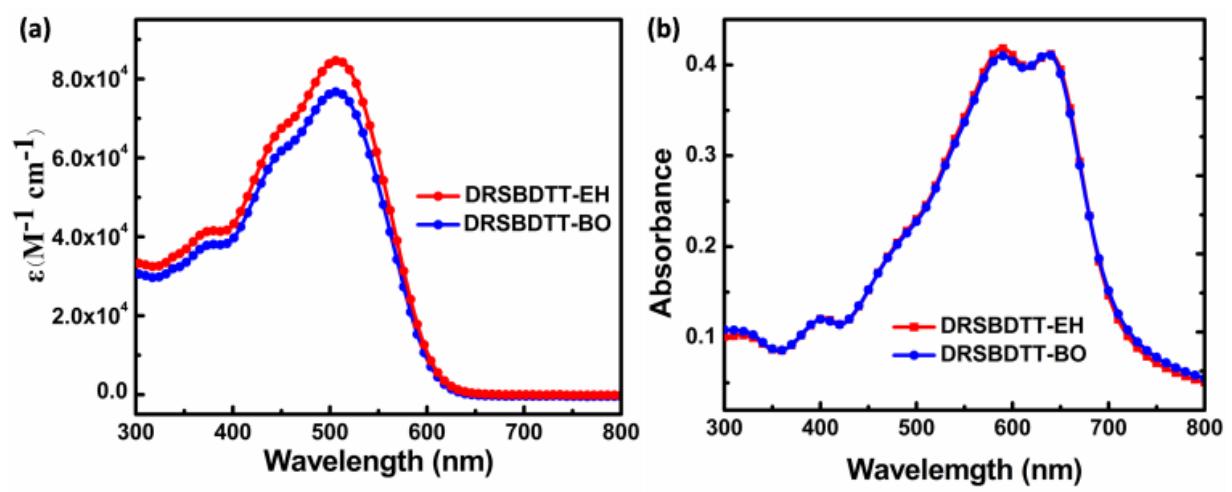

Fig. 1 Absorption spectra of DRSBDTT-EH and DRSBDTT-BO in (a) chloroform solution and (b) in films.

Fig.1 displayed the UV-vis absorption spectra of the two molecules. In dilute chloroform solution, DRSBDTT-EH and DRSBDTT-BO have similar absorption maxima (506 nm for DRSBDTT-EH and $508 \mathrm{~nm}$ for DRSBDTT-BO) and their corresponding absorption coefficients are $8.6 \times 10^{4}$ and $7.7 \times 10^{4} \mathrm{M}^{-1}$ $\mathrm{cm}^{-1}$, respectively. In the solid state, the spectra are broadened and red-shifted by $80 \mathrm{~nm}$ relative to their corresponding solution absorption spectra. More pronounced vibronic structures $(589 \mathrm{~nm}$, $638 \mathrm{~nm}$ ) showed up at the longer wavelength as an indicator of ordered structures in the thin films of the two molecules and their shapes are almost identical, indicating that the bulkiness of side 
chains has very little effect on the molecular packing. Two compounds possess similar optical band gaps of 1.71 and $1.73 \mathrm{eV}$, respectively, deduced from the onset of the thin film absorption. Cyclic voltammetry measurement in dichloromethane solution and internally calibrating using the ferrocene/ferrocenium of the $\left(\mathrm{Fc} / \mathrm{Fc}^{+}\right)$ redox couple were conducted to investigate the energy levels (Fig.S2). The highest occupied molecular orbital (HOMO) and lowest unoccupied molecular orbital (LUMO) calculated from the onset oxidation and reduction potentials, are -5.06 and $-3.33 \mathrm{eV}$ for DRSBDTT-EH and -5.03 and $-3.23 \mathrm{eV}$ for DRSBDTT-BO, respectively. The above data show that the length of alkylthiol substituted onto BDTT core has negligible influence on the basic physical properties of these two materials.

\subsection{Photovoltaic performance}

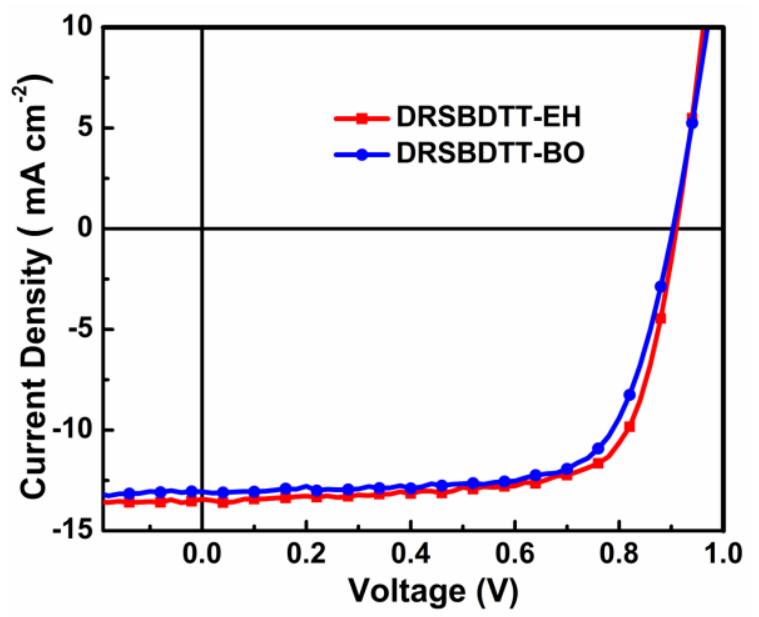

Fig. $2 J-V$ curves for the optimal devices of DRSBDTT-BO and DRSBDTT-EH under simulated AM $1.5 \mathrm{G}$ irradiation $\left(100 \mathrm{mWcm}^{-2}\right)$. 
Table 1 Photovoltaic parameters for the optimized DRSBDTT-BO and DRSBDTT-EH based devices.

\begin{tabular}{ccccc}
\hline Device & $V_{\mathrm{oc}}(\mathrm{V})$ & $J_{\mathrm{sc}}\left(\mathrm{mA} \mathrm{cm}^{-2}\right)$ & $F F(\%)$ & PCE $(\%)$ \\
\hline DRSBDTT-BO & 0.910 & 13.06 & 71.8 & $8.53(8.40 \pm 0.14)$ \\
\hline DRSBDTT-EH & 0.906 & 13.38 & 72.5 & $8.78(8.35 \pm 0.43)$ \\
\hline
\end{tabular}

Two small molecules as the electron donors were mixed with $\mathrm{PC}_{71} \mathrm{BM}$ and integrated into solution-processed OPVs with a $\begin{array}{lll}\text { conventional device } & \text { structure }\end{array}$ ITO/PEDOT:PSS/donor:acceptor/PrC ${ }_{60} \mathrm{MA} / \mathrm{Al} . \quad \mathrm{PrC}_{60} \mathrm{MA}$ is an efficient interfacial layer for cathodes developed by Alex K.-Y [43]. The details of device fabrication, measurements and optimization progress for two molecules were described in ESI. Without any treatment, DRSBDTT-EH:PC ${ }_{71} \mathrm{BM}(1: 0.8 \mathrm{w} / \mathrm{w})$ devices gave a moderate PCE of $7.26 \%$, with an open circuit voltage $\left(\mathrm{V}_{\mathrm{oc}}\right)$ of 0.941 $\mathrm{V}$, a short circuit current $\left(J_{\mathrm{sc}}\right)$ of $12.61 \mathrm{~mA} \mathrm{~cm}^{-2}$, and a fill factor $(\mathrm{FF})$ of $61.2 \%$. After solvent vapor annealing (SVA) treatment with $\mathrm{CS}_{2}$, the performance was significantly improved to $8.78 \%$, with $\mathrm{V}_{\mathrm{oc}}=$ $0.906 \mathrm{~V}, J_{\mathrm{sc}}=13.38 \mathrm{~mA} \mathrm{~cm}^{-2}$, and $\mathrm{FF}=72.5 \%$, which was ascribed to the enhanced absorption, increased phase separation and finely tuned morphology as indicated from the UV-Vis absorption, AFM and TEM images of the blend films with/without SVA respectively in SI. [44] For DRSBDTT-BO, a slightly low PCE of 6.90\% was achieved for the as-cast devices but a better PCE of $8.53 \%$ was obtained for 
device with SVA treatment. For comparison, the current density-voltage $(J-V)$ curves of the optimal devices based on two molecules were presented in Fig.2 and the corresponding photovoltaic parameters are summarized in Table 1. As shown in Table 1, DRSBDTT-EH and DRSBDTT-BO showed similar performances, as expected from their chemical structure. It is worth noting that DRSBDTT-BO based devices have better reproducibility than that of DRSBDTT-EH due to the better solubility of the former in chloroform. When comparing to alkylthiol-BDT analogue molecule DR3TSBDT, a slightly reduction in $\mathrm{V}_{\mathrm{oc}}$ is observed, which is on the contrary to the PTB7/PTB7-Th evolution, showing that signature of molecular design in polymer differs from that in small molecules.
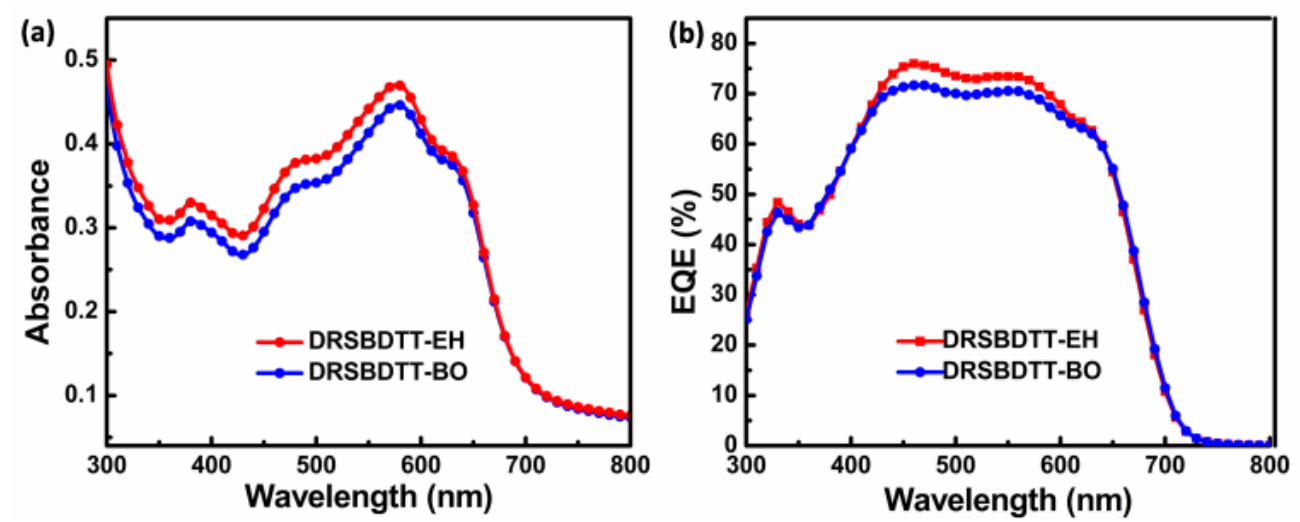

Fig. 3 (a) The UV-Vis absorption spectra of DRSBDTT-BO, DRSBDTT-EH:PC ${ }_{71} B M$ blend with SVA; (b) The EQE curves of DRSBDTT-BO and DRSBDTT-EH-based devices with SVA.

In order to investigate the effect of side chain length on the device performance, UV-Vis absorption spectra of the optimized 
blend films of the two molecules and the external quantum efficiency (EQE) were measured. As shown in Fig. 3a, the absorbance across the wavelength range of $300-650 \mathrm{~nm}$ of DRSBDTT-EH blend film is relatively higher than that of DRSBDTT-BO. As illustrated from the EQE curves (Fig. 3b), DRSBDTT-EH-based device bearing shorter side chain possessed higher EQE from 430-600 nm, which is consistent with the UV-Vis absorption spectra of blend film. The calculated $J_{\text {sc }}$ obtained by integration of the EQE curve are 12.80 and $12.46 \mathrm{~mA} \mathrm{~cm}^{-2}$ for the DRSBDTT-EH and DRSBDTT-BO based optimized devices respectively. They are within $5 \%$ mismatch compared with the $J_{\text {sc }}$ values obtained from the $J-V$ curves.
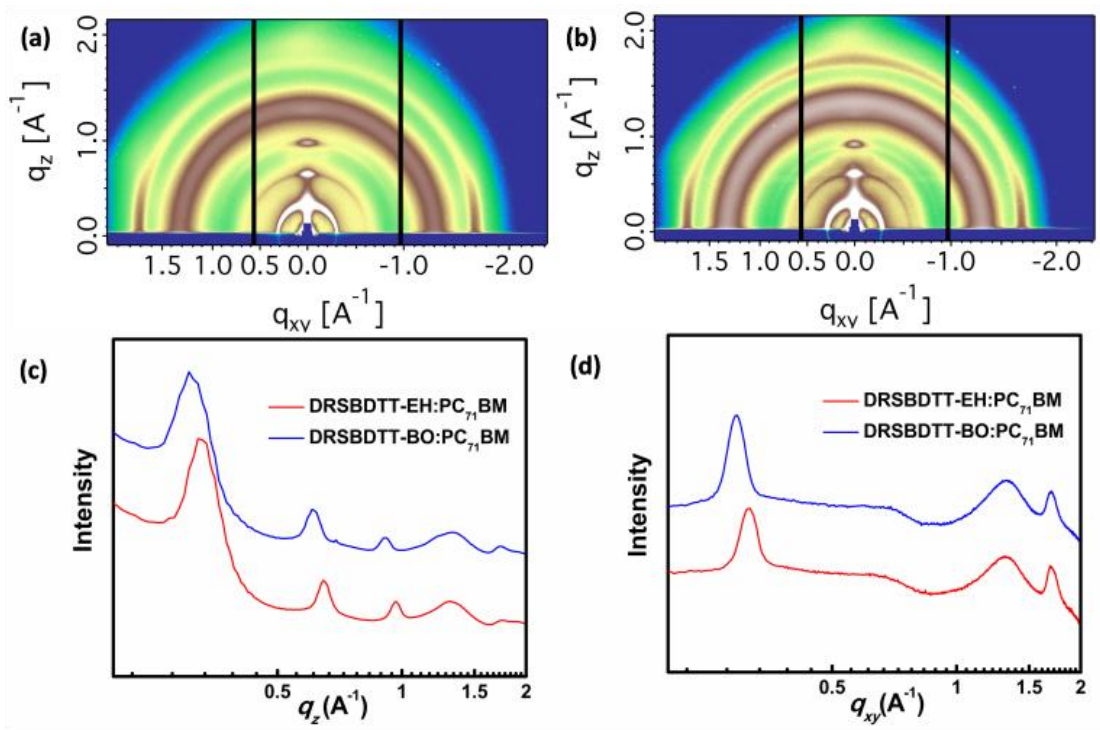

(d)

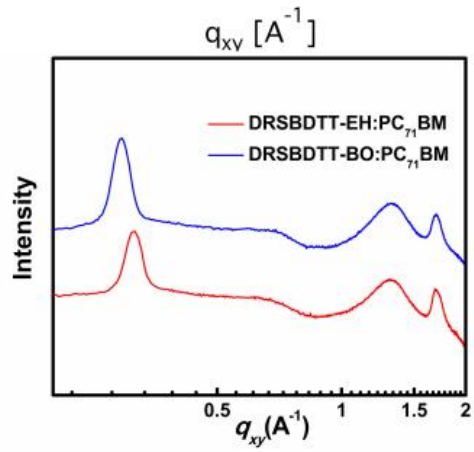

Fig. 4 GIXD diffraction patterns of the active layers: (a) DRSBDTT-EH:PC ${ }_{71} B M$ and (b) DRSBDTT-BO:PC ${ }_{71} \mathrm{BM}$ under their optimized conditions; (c) Out-of-plane line-cuts of GIXD; (d) In-the-plane line-cuts of GIXD. 
Table 2 Morphological data from GIXD.

\begin{tabular}{cccccc}
\hline Molecule & \multicolumn{3}{c}{$(100)$ Out of Plane } & \multicolumn{2}{c}{$(010)$ In the Plane } \\
\cline { 2 - 6 } & $\mathrm{q}\left(\AA^{-1}\right)$ & $\mathrm{d}(\AA)$ & Crystal size $(\AA)$ & $\mathrm{q}\left(\mathrm{A}^{-1}\right)$ & $\mathrm{d}(\AA)$ \\
\hline DRSBDTT-EH & 0.321 & 19.59 & 176 & 1.684 & 3.73 \\
\hline DRSBDTT-BO & 0.297 & 21.16 & 149 & 1.701 & 3.69 \\
\hline
\end{tabular}

To better understand the effect of the side chains on the photovoltaic performance, AFM and TEM were employed to study the morphology of the active layer. From AFM measurement (Fig. S5), the two molecules based optimized blend films with $\mathrm{PC}_{71} \mathrm{BM}$ were all smooth and uniform with small root-mean-square (RMS) roughnesss of 1.57 and $1.12 \mathrm{~nm}$, respectively. From TEM (Fig. S6), similar bi-continuous and interpenetrating network were observed for both molecules based blend films. GIXD was employed to further investigate structural order of the blend films. As depicted in Fig. 4a and b, both molecules exhibit good structure order, showing high orders of (h00) reflections along the $\mathrm{q}_{\mathrm{z}}$ direction, indicating a preferred edge-on orientation with good crystallinity. From Table 2, these two molecules have similar $\pi-\pi$ stacking distance, suggesting the alkyl length has a little effect on the molecule $\pi$ - $\pi$ stacking, which is consistent with the UV-Vis absorption results. The lamellar staking distance of DRSBDTT-EH:PC ${ }_{71} \mathrm{BM}$ is $19.59 \AA$, which is smaller than that of DRSBDTT-BO (21.16̊). The Scherrer equation correlation length of the lamellar stacking in the optimized DRSBDTT-EH blend (176 ^) is larger than DRSBDTT-BO blend 


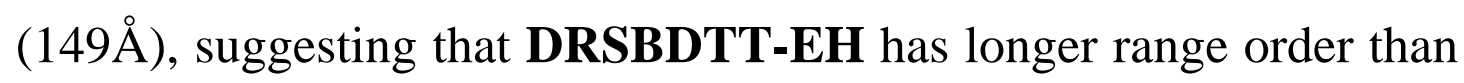
DRSBDTT-BO. The GIXD result is consistent with the hole mobility results measured by space-charge-limited current (SCLC) method (Fig. S8). The optimized DRSBDTT-EH based device gave hole mobility with a value of $5.45 \times 10^{-4} \mathrm{~cm}^{2} \mathrm{~V}^{-1} \mathrm{~s}^{-1}$, which is larger than that of DRSBDTT-BO based device $\left(2.95 \times 10^{-4} \mathrm{~cm}^{2} \mathrm{~V}^{-1} \mathrm{~s}^{-1}\right)$. However, the device performance for these two molecules are poorer than their analogue molecule DR3TSBDT, which are attributed to their weak absorption and relatively poorer morphologies compared with DR3TSBDT [39].

\section{Conclusions}

In conclusion, two new donor materials DRSBDTT-BO and DRSBDTT-EH with alkylthiothienyl substituted BDT as central unit and 3-ethylrhodanine as end groups have been designed for solution processed organic solar cells. It has been found that the EH and BO alkylthio chain length had nearly no influence on the molecular absorptions and energy levels. Though DRSBDTT-EH packed closer in (100) direction, it has no obvious effect on its electronic properties and device performance. The device performances of the two molecules are slightly inferior compared to that of alkylthiol-BDT analogue molecule DR3TSBDT, which comes from detailed morphological issues, requiring efforts in 
further investigation.

\section{Acknowledgments}

The authors gratefully acknowledge the financial support from MoST (2014CB643502), NSFC (51373078, 51422304 and 91433101), PCSIRT (IRT1257) and Tianjin city (13RCGFGX01121). TPR and FL were supported by Polymer-Based Materials for Harvesting Solar Energy (PhaSE) Energy Frontier Research Center funded by the U.S. Department of Energy, Office of Basic Energy

Sciences under award number DE-SC0001087.

\section{References}

[1] A. J. Heeger, Chem. Soc. Rev., 39, (2010), 2354-2371.

[2] F. C. Krebs, J. Fyenbo and M. Jørgensen, J. Mater. Chem, 20, (2010), 8994-9001.

[3] D. J. Lipomi and Z. Bao, Energy Environ. Sci., 4, (2011), 3314-3328.

[4] F. He and L. Yu, J. Phys. Chem. Lett., 2, (2011), 3102-3113.

[5] J.-D. Chen, C. Cui, Y.-Q. Li, L. Zhou, Q.-D. Ou, C. Li, Y. Li and J.-X. Tang, Adv. Mater., 27, (2015), 1035-1041.

[6] Y. Liu, J. Zhao, Z. Li, C. Mu, W. Ma, H. Hu, K. Jiang, H. Lin, H. Ade and H. Yan, Nat. Commun, 5, (2014), No. 5293.

[7] L. Ye, S Zhang, W Zhao, B Yang, Q Wang, J Hou, Sci. China Chem., 58, (2015), 248-256. 
[8] S. Liu, P. You, J. Li, J. Li, C.-S. Lee, B. S. Ong, C. Surya and F. Yan, Energy Environ. Sci., 8, (2015), 1463-1470.

[9] W. Yu, L. Huang, D. Yang, P. Fu, L. Zhou, J. Zhang and C. Li, J. Mater. Chem. A, 3, (2015), 10660-10665.

[10] S. H. Liao, H. J. Jhuo, P. N. Yeh, Y. S. Cheng, Y. L. Li, Y. H. Lee, S. Sharma and S. A. Chen, Sci. Rep, 4, (2014), 6813.

[11] D. Sun, D. Meng, Y. Cai, B. Fan, Y. Li, W. Jiang, L. Huo, Y. Sun and Z. Wang, J. Am. Chem. Soc., 137, (2015), 11156-11162.

[12] Y. Zhong, M. T. Trinh, R. Chen, G. E. Purdum, P. P. Khlyabich, M. Sezen, S. Oh, H. Zhu, B. Fowler, B. Zhang, W. Wang, C. Y. Nam, M. Y. Sfeir, C. T. Black, M. L. Steigerwald, Y. L. Loo, F. Ng, X. Y. Zhu and C. Nuckolls, Nat. Commun, 6, (2015), 8242.

[13] E. Zhou, J. Cong, Q. Wei, K. Tajima, C. Yang and K. Hashimoto, Angew Chem. Int. Ed., 50, (2011), 2799-2803.

[14] E. Zhou, J. Cong, M. Zhao, L. Zhang, K. Hashimoto and K. Tajima, Chem. Commun., 48, (2012), 5283-5285.

[15] E. Zhou, J. Cong, K. Hashimoto and K. Tajima, Adv. Mater. 25, (2013), 6991-6996.

[16] E. Zhou, M. Nakano, S. Izawa, J. Cong, I. Osaka, K. Takimiya and K. Tajima, ACS Macro. Lett, 3, (2014), 872-875.

[17] Y. Geng, J. Huang, K. Tajima, Q. Zeng and E. Zhou, Polymer, 63, (2015), 164-169. 
[18] H.-W. Lin, J.-H. Chang, W.-C. Huang, Y.-T. Lin, L.-Y. Lin, F. Lin, K.-T. Wong, H.-F. Wang, R.-M. Ho and H.-F. Meng, J. Mater. Chem. A, 2, (2014), 3709 .

[19] Y. H. Chen, L. Y. Lin, C. W. Lu, F. Lin, Z. Y. Huang, H. W. Lin, P. H. Wang, Y. H. Liu, K. T. Wong, J. Wen, D. J. Miller and S. B. Darling, J. Am. Chem. Soc., 134, (2012), 13616-13623.

[20] L. Y. Lin, Y. H. Chen, Z. Y. Huang, H. W. Lin, S. H. Chou, F. Lin, C. W. Chen, Y. H. Liu and K. T. Wong, J. Am. Chem. Soc., 133, (2011), $15822-15825$.

[21] B. Walker, C. Kim and T.-Q. Nguyen, Chem. Mater., 23, (2011), 470-482.

[22] J. Roncali, P. Leriche and P. Blanchard, Adv. Mater., 26, (2014), $3821-3838$.

[23] Y. Lin, Y. Li and X. Zhan, Chem. Soc. Rev., 41, (2012), 4245.

[24] B. Kan, M. Li, Q. Zhang, F. Liu, X. Wan, Y. Wang, W. Ni, G. Long, X. Yang, H. Feng, Y. Zuo, M. Zhang, F. Huang, Y. Cao, T. P. Russell and Y. Chen, J. Am. Chem. Soc., 137, (2015), 3886-3893.

[25] Y. Lin, L. Ma, Y. Li, Y. Liu, D. Zhu and X. Zhan, Adv. Energy Mater., 4, (2014), 1300626.

[26] Y. Lin, L. Ma, Y. Li, Y. Liu, D. Zhu and X. Zhan, Adv. Energy Mater., 3, (2013), 1166-1170.

[27] H. Bai, Y. Wang, P. Cheng, Y. Li, D. Zhu and X. Zhan, ACS Appl. 
Mater. Interfaces, 6, (2014), 8426-8433.

[28] Y. Liang, Z. Xu, J. Xia, S. T. Tsai, Y. Wu, G. Li, C. Ray and L. Yu, Adv. Mater., 22, (2010), E135-138.

[29] X. Ouyang, R. Peng, L. Ai, X. Zhang and Z. Ge, Nat. Photonics, 9, (2015), 520-525.

[30] C. Liu, C. Yi, K. Wang, Y. Yang, R. S. Bhatta, M. Tsige, S. Xiao and X. Gong, ACS Appl. Mater. Interfaces, 7, (2015), 4928-4935.

[31] Z. He, B. Xiao, F. Liu, H. Wu, Y. Yang, S. Xiao, C. Wang, T. P. Russell and Y. Cao, Nat. Photonics, 9, (2015), 174-179;

[32] Y. Lin, J. Wang, Z. G. Zhang, H. Bai, Y. Li, D. Zhu and X. Zhan, Adv. Mater., 27, (2015), 1170-1174.

[33] J. Zhao, Y. Li, H. Lin, Y. Liu, K. Jiang, C. Mu, T. Ma, J. Y. L. Lai, H. Hu, D. Yu and H. Yan, Energy Environ. Sci., 8, (2015), 520-525.

[34] Y. Chen, X. Wan and G. Long, Acc. Chem. Res., 46, (2013), $2645-2655$.

[35] M. Li, W. Ni, X. Wan, Q. Zhang, B. Kan and Y. Chen, J. Mater. Chem. A, 3, (2015), 4765-4776.

[36] C. Cui, W.-Y. Wong and Y. Li, Energy Environ. Sci., 7, (2014), 2276-2284.

[37] L. Ye, S. Zhang, W. Zhao, H. Yao and J. Hou, Chem. Mater, 26, (2014), 3603-3605.

[38] K. Feng, X. Xu, Z. Li, Y. Li, K. Li, T. Yu and Q. Peng, Chem. 
Commun., 51, (2015), 6290-6292.

[39] B. Kan, Q. Zhang, M. Li, X. Wan, W. Ni, G. Long, Y. Wang, X. Yang, H. Feng and Y. Chen, J. Am. Chem. Soc., 136, (2014), 15529-15532. [40] J. Zhou, Y. Zuo, X. Wan, G. Long, Q. Zhang, W. Ni, Y. Liu, Z. Li, G. He, C. Li, B. Kan, M. Li and Y. Chen, J. Am. Chem. Soc., 135, (2013), 8484-8487.

[41] C. Cui, W.-Y. Wong and Y. Li, Energy Environ. Sci., 7, (2014), 2276-2284.

[42] J. Zhou, X. Wan, Y. Liu, G. Long, F. Wang, Z. Li, Y. Zuo, C. Li and Y. Chen, Chem. Mater., 23, (2011), 4666-4668.

[43] C. Li, C. Chueh, H. Yip, K. O'Malley, W. Chen, A. K. Y. Jen, J. Mater. Chem., 22, (2012), 8574.

[44] M. Li, F. Liu, X. Wan, W. Ni, B. Kan, H. Feng, Q. Zhang, X. Yang, Y. Wang, Y. Zhang, Y. Shen, T. P. Russell and Y. Chen, Adv. Mater., 2015, DOI: 10.1002/adma.201502645. 